\title{
Pessoas surdas na aula de Matemática... E agora? (Análise de uma práxis com materiais didáticos)
}

Resumo: Considerando a inclusão como um paradigma necessário à democratização de espaços, este artigo objetiva apresentar a constituição de uma Sequência de Tarefas relacionada à aprendizagem de números reais, por meio de materiais didáticos, desenvolvida no $1^{\circ}$ ano do Ensino Médio de uma escola da comunidade surda. A partir de um estudo de caso, dados do perfil discente, da observação participante e de uma Sequência de Tarefas foram analisados pela ótica qualitativa e semiocognitiva. Entre os resultados, constata-se que o tangram propiciou maior mobilização de representações fracionárias e apreensões figurais. A calculadora, régua e compasso permitiram explorar representações decimais e construções geométricas, estabelecendo pontos sob a reta numérica. O livro didático desencadeou a necessidade de tradução para a Libras na abordagem das representações em português e linguagem matemática. Conclui-se que tais materiais didáticos contribuíram para a coordenação de representações, tomando como ponto de partida o figural e favorecendo a apreensão conceitual.
Lucas José de Souza

Mestra em Educação Matemática e Ensino de Física. Professora do

Colégio Estadual Manoel Ribas, em Santa Maria. Rio Grande do Sul,

Brasil.

(iD) orcid.org/0000-0001-9542-2051

$\triangle$ lucas.js@hotmail.com

Rita de Cássia Pistóia

Mariani

Doutora em Educação Matemática.

Professora do Programa de PósGraduação em Educação Matemática e Ensino de Física da Universidade Federal de Santa Maria (UFSM). Rio Grande do Sul, Brasil

(iD) orcid.org/0000-0002-8202-8351

\rcpmariani@yahoo.com.br

Recebido em 25/04/2021 Aceito em 02/07/2021 Publicado em 25/08/2021

Palavras-chave: Libras. Educação Matemática Inclusiva. Representações Semióticas. Ensino Médio.

\section{Deaf people in Math classes... What is next? (Analysis of a praxis with pedagogical materials)}

Abstract: Considering inclusion as a necessary paradigm for the democratization of spaces, this paper aims to present the constitution of a Task Sequence related to learning real numbers, through pedagogical materials, developed in the $1^{\text {st }}$ year of High School at a deaf community school. From a case study, data of the student profile, participant observation and a Task Sequence were analyzed in a qualitative and semio-cognitive perspective. The results show the tangram provided greater mobilization of fractional representation form and figure apprehensions. The calculator, ruler and compass allowed to explore decimal representations and geometric constructions and to establish dots on the number line. The textbook triggered the need for translation into Libras in the approach to Portuguese language representations and mathematical symbology. It was concluded that such didactic materials contributed to the coordination of representations, taking the figural as a starting point and favoring conceptual apprehension.

Keywords: Libras. Inclusive Mathematics Education. Semiotic Representations. High School.

\section{Personas sordas en clase de Matemáticas... ¿Y ahora qué? (Análisis de una praxis con materiales didácticos)}


Resumen: Considerando la inclusión como paradigma necesario para democratización de los espacios, este artículo tiene como objetivo presentar la constitución de una Secuencia de Tareas relacionada con el aprendizaje de números reales, a través de materiales didácticos, desarrollada en el primer año de secundaria en una escuela de la comunidad sorda. A partir de un estudio de caso, se analizan datos del perfil estudiantil, la observación participante y una Secuencia de Tareas en una perspectiva cualitativa y semio-cognitiva. Los resultados muestran que el tangram proporcionó mayor movilización de representaciones fraccionarias y aprehensiones de figuras. La calculadora, regla y compás permitieron explorar representaciones decimales y construcciones geométricas, estableciendo puntos en la recta numérica. El libro de texto desencadenó la necesidad de traducción a Libras en el enfoque de representaciones en portugués y lenguaje matemático. Se concluye que dichos materiales contribuyeron para coordinación de representaciones, partiendo de figuras y favoreciendo la aprehensión conceptual.

Palabra clave: Libras. Educación Matemática Inclusiva. Representaciones Semióticas. Enseñanza Media.

\section{Considerações prévias: Educação Matemática Inclusiva no contexto da surdez}

A pessoa surda desenvolve capacidades cognitivas especificamente visuais, que superpõem a impossibilidade de ouvir. Mesmo que as línguas orais e de sinais sejam processadas em algumas vias cognitivas comuns, as línguas de sinais associam e desenvolvem vias neurológicas específicas ao processamento de estímulos pela observação, através do sentido sensorial da visão (SACKS, 1998).

Por outro lado, o pensamento abstrato matemático pode se desenvolver mediante a manipulação física, com recursos concretos que explorem relações e propriedades matemáticas, ou seja, materiais didáticos manipuláveis (LORENZATO, 2006). Por meio de tarefas matemáticas planejadas, esses materiais podem contribuir para o estabelecimento de conjecturas sobre entes matemáticos, pautados na observação manipulativa e reflexão, inicialmente com suporte ao concreto.

Assim, o processo de aprendizagem centra-se na descoberta de relações para estabelecer generalizações conceituais, o que se distingue da prática mnemônica de regras e fórmulas. Nesse contexto, materiais manipuláveis tomam outro patamar quando considerados na educação de pessoas surdas, por estimular a construção de relações visuais e espaciais, portanto, explorá-los em aulas de Matemática na comunidade surda não é só aconselhável, mas sim essencial (BORGES e NOGUEIRA, 2013).

Nesse sentido, ao analisar a produção stricto sensu, disponível no banco de Teses 
e Dissertações da Coordenação de Aperfeiçoamento de Pessoal de Nível Superior (CAPES), Souza, Guimarães e Mariani (2018) mapearam 66 teses e dissertações que tangem a educação matemática de pessoas surdas. Apesar de identificar uma grande incidência do uso de materiais didáticos nas pesquisas mapeadas, apenas cinco obras se valeram do tangram, sendo o material utilizado principalmente para explorar formas geométricas, sem estabelecer relações com propriedades de números reais (GIL, 2007; TEIXEIRA, 2008; JESUS, 2014; ROCHA, 2014; SALES, 2013). Por outro lado, tais estudos concordam que materiais manipuláveis potencializam a exploração heurística, direcionam organizações de pensamento e a explicação/comunicação de ideias.

Pinheiro et al. (2020), ao analisar artigos em 75 revistas (Qualis entre A1 e B2), também estabelecem um mapeamento sob os princípios de Biembengut (2008) e identificam que, no âmbito da resolução de problemas, há igualmente um baixo quantitativo de pesquisas com pessoas surdas. Além disso, a revisão de literatura de Soares e Sales (2018, p. 50), a partir da análise de 31 teses ou dissertações, evidencia que "nenhuma das pesquisas analisadas voltou-se para a realidade do Ensino Médio".

Nesse contexto, foi constituída uma dissertação (SOUZA, 2019), a qual se vincula este artigo. Nela, observa-se uma práxis ${ }^{1}$ na comunidade surda que promove discussões acerca do objeto matemático números reais, abordado em uma turma do $1^{\circ}$ ano do Ensino Médio. Para tanto, adota-se o aporte teórico dos registros de representação semiótica, bem como o uso de materiais didáticos. Vale ressaltar que se adota a terminologia material didático para denominar concomitantemente o material manipulável (tangram) e os recursos didáticos - o livro didático, a calculadora e a régua e compasso - envolvidos nessa pesquisa, valorizando discussões na literatura especializada, como àquelas promovidas por Lorenzato (2006), que diferenciam tais instrumentos.

Posto isso, o presente artigo tem o objetivo de apresentar a constituição de uma Sequência de Tarefas relacionada à aprendizagem de números reais, por meio de materiais didáticos, desenvolvida no $1^{\circ}$ ano do Ensino Médio de uma escola da comunidade surda.

\footnotetext{
${ }^{1}$ Para Vázquez (2003) a palavra "prática” comumente está associada a um senso utilitário, uma ação que tem um fim em si mesmo. No entanto, os contextos de ensino e aprendizagem extrapolam a carga utilitária, os atos de criar, inventar, descobrir estimulados na escola constituem objetivos para além das ações no processo. Assim, entende-se por práxis um objeto de interpretação do mundo e guia de sua transformação, envolvendo uma consciência reflexiva, que "indica as condições que tornam possíveis a transição da teoria para a prática, e garante a unidade íntima de uma e outra” (VÁZQUEZ, 2003, p. 30).
} 
Sendo assim, considera-se o lócus da Escola Estadual de Educação Especial Dr. Reinaldo Fernando Cóser, localizada em Santa Maria — RS, e a dinamização de uma Sequência de Tarefas com 42 atividades.

Para tanto, além desta introdução, tecemos cinco seções, sendo que na primeira o contexto das escolas para pessoas surdas é abordado. Em seguida, se embasa teoricamente a construção das tarefas matemáticas, considerando os registros de representação semiótica e o objeto números reais. Posteriormente, o escopo metodológico e os instrumentos exploratórios no contato com a comunidade escolar são delineados. A partir destas bases, se explicitam análises dos materiais didáticos utilizados na Sequência de Tarefas. Ao fim, são compostas algumas considerações relacionadas a este desfecho.

\section{Escolas de pessoas surdas (por quê?): um olhar no enlevo histórico}

Ao analisar a trajetória histórica da educação de pessoas surdas, desvelam-se caminhos que não respeitaram a principal demanda da comunidade: a língua de sinais. Entre os séculos XVI e XVIII (E.C.) emergem duas correntes educativas para pessoas surdas: o oralismo e o gestualismo. De um lado Samuel Heinicke (1727-1790), pressupondo que o pensamento só se desenvolve mediante à língua oral, de outro Charles Michel L'Epée (1712-1789) pleiteando o uso de formas comunicativas visuais.

Com acalorados debates, ambas correntes coexistiram até a proibição do uso das línguas de sinais em 1880, no II Congresso Internacional de Educação dos Surdos, vulgo Congresso de Milão (LACERDA, 1998). Cabe destacar que as pessoas surdas docentes foram retiradas do congresso no momento da votação para essa decisão (SACKS, 1998).

Contudo, a educação oralista formou "meros repetidores de itens lexicais descontextualizados, incapazes de trocar ideias com estranhos e, até com as pessoas com quem conviviam mais diretamente" (COUTINHO, 2015, p. 66). Com o fracasso oralista, a resiliência da comunidade surda encontrou um pequeno espaço para germinar, "raramente se encontrava uma escola ou instituição para surdos que não tivesse desenvolvido, às margens do sistema, um modo próprio de comunicação através dos sinais" (LACERDA, 1998, p. 75).

Na gradativa queda do oralismo, algumas abordagens "híbridas" são conciliadas para pessoas surdas, em uma mistura má combinada entre uso de sinais e oralização. No 
Brasil, a Comunicação Total é o principal desses hibridismos, que sucumbiu por desrespeitar, novamente, o anseio da comunidade surda pela língua de sinais. O método prometeu o estímulo da comunicação visual, porém na prática efetivou o treinamento oral, sendo o uso de sinais meramente acessório (ZANQUETTA, 2015; LACERDA, 1998).

Em contexto hodierno, a constante luta da comunidade surda garantiu muitos direitos. É possível citar o reconhecimento legal da Língua Brasileira de Sinais, doravante Libras, como idioma (BRASIL, 2002), a disposição de Tradutoras Intérpretes de Língua de Sinais e Língua Portuguesa (TILSP) para pessoas surdas na educação pública (BRASIL, 2002, 2005, 2010) e a inclusão da Libras como componente curricular obrigatório em cursos de licenciatura e fonoaudiologia (BRASIL, 2005).

Além disso, a garantia da educação como direito de todas as pessoas e a melhoria da educação inclusiva está prevista na constituição brasileira (BRASIL, 1988), na declaração de Salamanca (BRASIL, 1994) e no artigo 59 da Lei de Diretrizes e Bases da Educação Nacional (BRASIL, 1996). Tais legislações deram solo à comunidade surda para o acolhimento de suas reivindicações: uma pedagogia surda.

Assim, em 1999 a comunidade surda constrói o documento A educação que nós surdos queremos, que pauta a criação de escolas com atendimento específico para pessoas surdas, permitindo a constituição de identidades culturais que valorizem a língua de sinais (RIO DE JANEIRO, 1999). Em contraste, o Estatuto da Pessoa com Deficiência (BRASIL, 2015) garante o direito da pessoa surda à Educação Bilíngue, norteada pelo princípio de que todo processo educativo deve agenciar a Libras como primeira língua e o Português, na modalidade escrita, como idioma secundário.

A necessidade de uma escola específica para pessoas surdas não se dá pelo caráter de deficiência, mas sim pela diferença linguística. Para Barbosa (2009), crianças surdas podem apresentar dificuldades no desenvolvimento da linguagem. Um dos fatores que justificam esse fato se deve à origem em famílias ouvintes, que não conhecem a língua de sinais. Assim, as escolas para pessoas surdas podem fomentar necessidades comunicativas, fornecendo condições de desenvolvimento da linguagem visuoespacial. Segundo o Projeto Político Pedagógico da Escola Estadual de Educação Especial Dr. Reinaldo Fernando Cóser, estudantes dos anos iniciais podem ingressar na instituição sem ter adquirido a Libras (RIO GRANDE DO SUL, 2018). 
A “inclusão" de pessoas surdas na educação básica regular, em alguns casos, pode ser posta em prática com a simples inserção de TILSP em salas de aula. Cabe perguntar: uma criança que não adquiriu linguagem compreenderá uma tradução do Português para a Libras? Se a escola regular não tiver condições de uma alfabetização plena de toda classe estudantil em modalidade bilíngue (Libras e Português), tampouco poderá ser "um centro de encontro com o semelhante para produção inicial da identidade surda" (RIO DE JANEIRO, 1999, p. 5).

A educação inclusiva entende a igualdade e a diferença como inseparáveis, visando a equidade social e equilibrando desigualdades que geram exclusão. Assim, as escolas específicas para pessoas surdas têm um valor de reparação histórica, que visa compensar as profundas lacunas vergadas pelo movimento oralista, todavia ainda ocupam poucos espaços em nossa sociedade. No Rio Grande do Sul, o projeto Produções culturais surdas no contexto da educação bilíngue, coordenado na Universidade Federal de Santa Maria pela professora Márcia Lise Lunardi-Lazzarin, mapeou tais escolas no estado (KARNOPP, KLEIN e LUNARDI-LAZZARIN, 2018), conforme Quadro 1.

Quadro 1: Escolas bilíngues específicas para pessoas surdas no Rio Grande do Sul

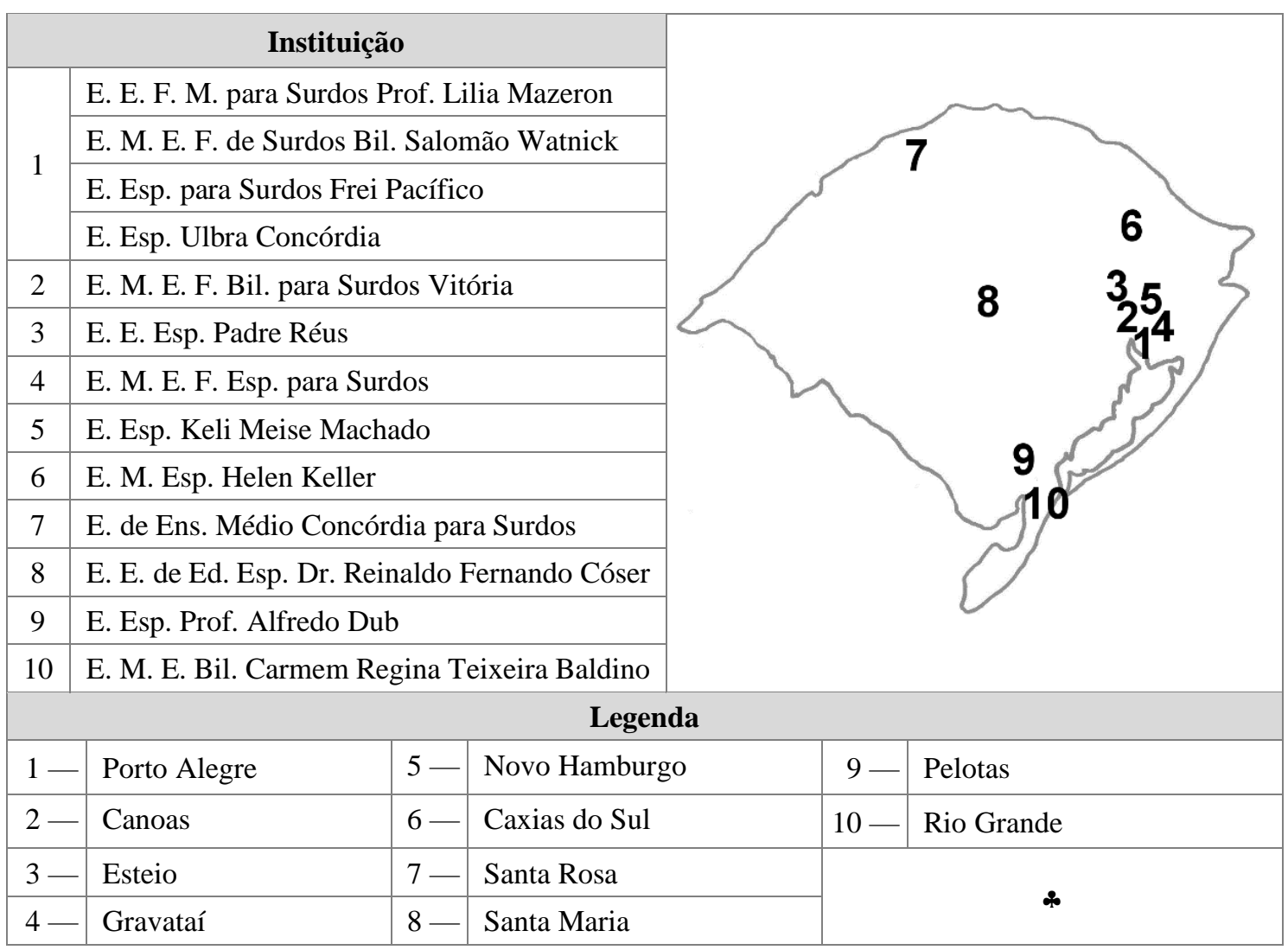

FONTE: Produzido pelas Autoras (Baseado em Karnopp, Klein e Lunardi-Lazzarin, 2018) 
Em Santa Maria — RS, a discussão de uma escola para pessoas surdas é iniciada em 1996, após a Semana Estadual da Pessoa com Deficiência organizada pela $8^{\text {a }}$ Coordenadoria Regional de Educação. O evento propiciou uma união entre a Associação dos Surdos de Santa Maria e docentes de pessoas surdas, que reivindicaram a reformulação da pedagogia surda no município. Com isso, em 1998 foi criada e denominada a Escola Estadual de Educação Especial Dr. Reinaldo Fernando Cóser (EEEERFC), que inicia as atividades em março de 2001 (RIO GRANDE DO SUL, 2018).

Como pilar pedagógico, a EEEERFC destaca os princípios da Educação Bilíngue, firmando a meta de garantia do desenvolvimento da linguagem, do pensamento e da construção do conhecimento através da Libras utilizada durante toda interação no ambiente escolar (RIO GRANDE DO SUL, 2018).

Devido à privação linguística imposta aos surdos, dentro das próprias famílias, levando em conta que a maioria dos surdos são membros de família de ouvintes que geralmente não sabem a língua de sinais, os surdos ingressam na escola com um precário conhecimento de mundo, diferente das crianças ouvintes que recebem estímulos constantes desde seu nascimento, pois muitas experiências vividas pela maioria das crianças, não são acessíveis à criança surda. (RIO GRANDE DO SUL, 2018, p. 5).

Além do desafio de propiciar acesso linguístico, a instituição atende jovens e crianças surdas com deficiência, como é o caso de pessoas surdas com paralisia cerebral, autistas, surdocegas etc., contando com atendimento educacional especializado e diferenciado. Fornecido esse panorama sobre a comunidade escolar surda, em seguida se busca estabelecer um diálogo teórico da Educação Matemática que pode colaborar com pontos de partida que corroborem com uma práxis na pedagogia surda.

\section{Educação para pessoas surdas por meio de representações semióticas}

A teoria dos registros de representação semiótica firma a compreensão da peculiaridade sobre os conceitos matemáticos que não existem no mundo real, apenas sendo acessíveis por meio de representações (DUVAL, 2003). Assim, são entendidas como representações semióticas aquelas utilizadas na linguagem matemática — sistemas variados para escritura de números, notações simbólicas, algébricas e lógicas, figuras geométricas, gráficos cartesianos, diagramas... - e a língua natural (DUVAL, 2011).

Cada sistema representativo tem regras próprias de funcionamento, sendo desenvolvimento conceitual matemático propiciado pela mobilização sinérgica de, pelo 
menos, dois sistemas de representação para um mesmo objeto (DUVAL, 2011). Por exemplo, a mobilização da representação fracionária não basta para conceituar o ente número racional, é preciso compreendê-lo em representação numérica decimal e percentual (DAMM, 2006), ainda por meio de figuras (representação icônica), como ponto sobre a reta numérica (representação geométrica) e com a designação/escrita em língua natural.

As representações figurais - neste caso, icônica e geométrica — têm unidades de significado interpretadas simultaneamente em uma organização espacial, o que converge com a estrutura comunicativa utilizada na língua de sinais (FRIZZARINI, 2014), portanto considera-se a importância destes registros na construção e dinamização da Sequência de Tarefas. Por exemplo, a reprodução dos contornos de peças do tangram no papel gera representações icônicas de figuras planas, as análises da área e medidas de lados nessas figuras oportunizaram transformações para outros sistemas representativos.

A unidade de área definida para mobilizar números racionais foi o quadrado formado pelas sete peças do tangram, por facilitar conjecturas de uma relação parte-todo no recurso. Já na mobilização de números irracionais, a unidade foi alterada, tomando a medida do lado da peça quadrada como unitária (Figura 1), para evitar confusões com representações fracionárias irracionais como $\frac{\sqrt{2}}{2}$ nesse primeiro momento.

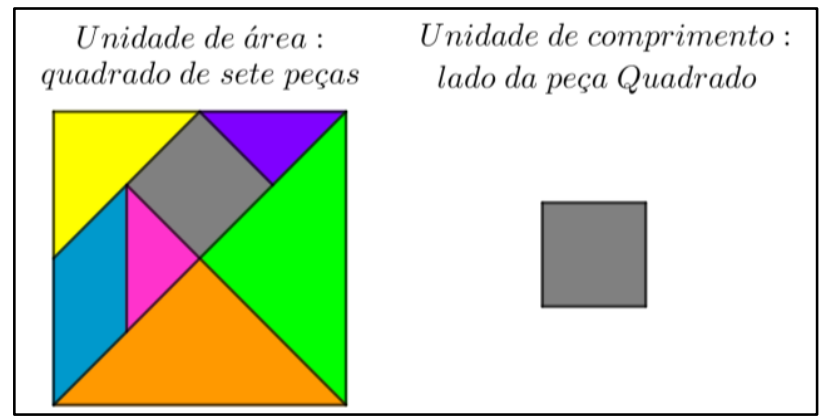

Figura 1: Representação icônica das duas medidas unitárias definidas nas atividades (Acervo da Pesquisa)

No caso dos números racionais, sobreposições das peças no contorno do quadrado unitário possibilitaram estabelecer uma relação parte-todo, que mobilizou representações fracionárias determinando o valor da área de cada peça. Quanto a peça Triângulo Grande, quatro destas formam o quadrado unitário, já para o Triângulo Médio são necessárias oito peças, e para o Triângulo Pequeno dezesseis peças. Desta forma, podem ser mobilizadas as representações $\frac{1}{4}, \frac{1}{8} \mathrm{e} \frac{1}{16}$, como respectivas medidas de área de cada peça supracitada. 
Isso posto, uma atividade matemática que pode ser realizada no material é a operação $\left[\frac{1}{4}+\frac{1}{8}+\frac{2}{16}\right]$. Ao organizar as peças Triângulo Grande, Triângulo Médio e duas peças Triângulo Pequeno sobre o contorno unitário, verifica-se que elas cobrem a "metade" da área, ou seja, um meio (Figura 2).

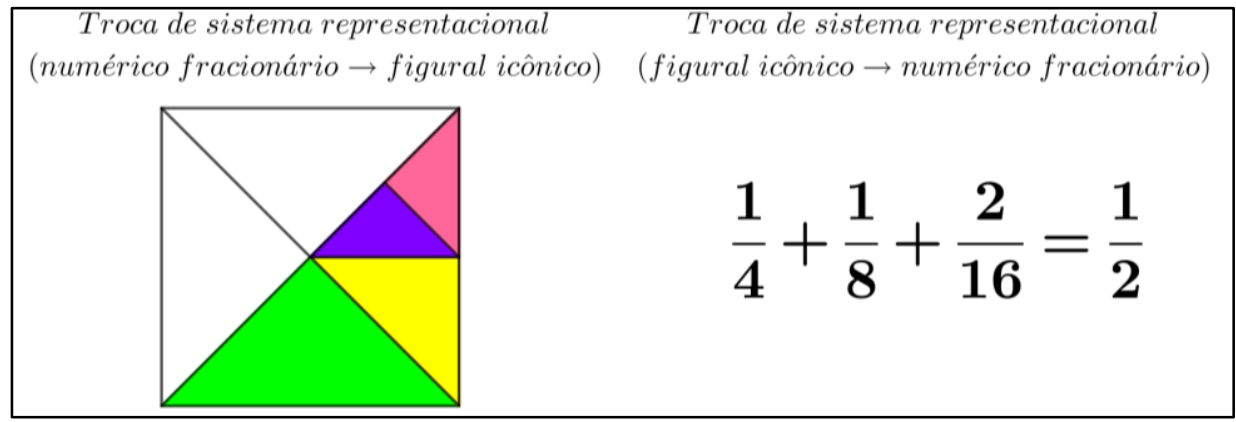

Figura 2: Exemplo de uma operação de adição com as peças do tangram (Acervo da Pesquisa)

O tangram desvela o estabelecimento de operações visuais sob figuras geométricas, que oportunizam atribuir sentidos a operações com números racionais, como ilustra a Figura 2. Esse desenvolvimento potencializa o estudo de operações numéricas, pois a manipulação que organiza as peças oportuniza a observação heurística da "metade" do contorno do quadrado unitário estar "preenchida".

Quanto ao estudo relacionado à irracionalidade, contemplam-se as orientações da Base Nacional Comum Curricular (BRASIL, 2017), na qual a medida $\sqrt{2}$ unidades de comprimento (u.c.) é obtida a partir do teorema de Pitágoras e o segmento diagonal de um quadrado de lado unitário - a peça quadrada do tangram. Para fins de explicação, o problema de dobrar a área de um quadrado unitário é resolvido a seguir (Figura 3), com suporte às formas de peças do tangram - as setas indicam operações figurais, respectivamente de troca, reorganização e inclusão de peças.

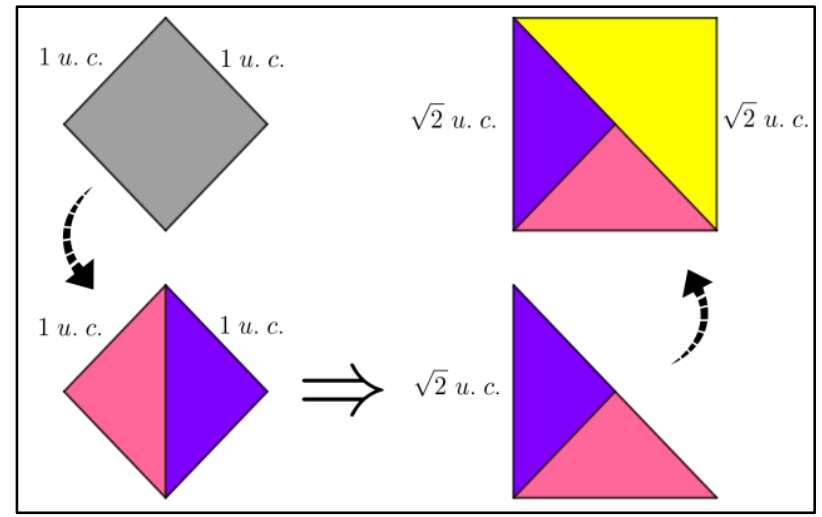

Figura 3: Clássico problema de dobrar a área do quadrado resolvido com o tangram (Acervo da Pesquisa) 
A área da peça Quadrado do tangram é congruente com a área de duas peças Triângulo Pequeno, estas podem ser reorganizadas sob a forma da peça Triângulo Médio sem alteração de sua área. Unindo, então, duas peças Triângulo Pequeno (1 unidade de área) e uma peça Triângulo Médio (1 unidade de área), obtêm-se um quadrado com área igual a 2, isto é, o dobro da área da peça Quadrado. Além disso, o lado do quadrado obtido é congruente ao segmento diagonal da peça Quadrado.

Para Duval (2012a; 2012b), a análise de figuras é interposta por quatro processos mentais: a apreensão perceptiva, na identificação de traços, pontos, segmentos, regiões etc.; a apreensão discursiva, que se dá em relações entre qualidades identificadas no discurso/enunciado/legendas e a imagem; a apreensão sequencial, na reprodução/construção da figura geométrica; e por fim, a apreensão operatória, em modificações nos processos de decomposição da figura (mereológica), de ampliação ou redução (ótica) ou de rotações e translações (posicional).

Não obstante, tais operações estão alicerçadas na perspectiva visual e espacial, que é fundamental para a Libras e para o desenvolvimento do pensamento na comunidade surda (GESSER, 2009). Além disso, as quatro apreensões em Geometria são potencializadas pelas conjecturas e manipulações de peças oportunizadas pelo tangram, contribuindo com o pensamento matemático por auxiliar na resolução das tarefas estabelecendo o raciocínio lógico (DUVAL, 2012a; 2012b).

\section{Fundamentação metodológica: o campo de pesquisa e as ações a priori}

Particularmente na EEEERFC, lócus desta pesquisa ${ }^{2}$, a práxis consolida especificidades identitárias da comunidade surda, estabelecendo uma diferença linguístico-cultural em relação às escolas regulares. A instituição atende estudantes de Santa Maria e região em três turnos, nos quais se distribuem: Educação Infantil, Ensino Fundamental, Ensino Médio, Curso Normal e Educação para Jovens e Adultos (Ensino Fundamental). O quadro de profissionais conta com pessoas surdas ou fluentes em Libras, sendo 25 cargos de docência, 2 de monitoria e 7 para funcionáries ${ }^{3}$.

\footnotetext{
2 Pesquisa aprovada pelo Comitê de Ética na Pesquisa da Universidade Federal de Santa Maria, sob o número de protocolo 99248918.1.0000.5346.

${ }^{3} \mathrm{Na}$ escrita utilizamos, em alguns casos, a letra "e" como desinência nominal neutra de gênero.
} 
Por estudar o fenômeno com base em distintas fontes de evidências e estabelecer análises a partir de convergências identificadas com um grupo determinado, em um contexto real, consideram-se os procedimentos técnicos de um estudo de caso (YIN, 2005). Diante das variáveis plurais e culturais do contexto escolar, as quais demandam distintas fontes para a produção/análise de dados (LÜDKE e ANDRÉ, 1986), a pesquisa se vale da abordagem qualitativa. Por isso, uma tríade de ações a priori foi planejada para preambular as análises da pesquisa e estabelecer uma inserção prévia com a turma de estudantes - Observação Participante de aulas, Questionário Semiestruturado do perfil da turma e Tarefa Prognóstica.

Para buscar informações sobre a realidade do desenvolvimento de uma aula no contexto da comunidade surda, foi efetuada a Observação Participante de 5 horas/aula na turma de $1^{\circ}$ ano do Ensino Médio que participou da pesquisa. Tais observações contribuíram no sentido de desvelar paradigmas e estratégias em aulas de Matemática para pessoas surdas e foram registradas em um diário de bordo, que se trata de um caderno em que se anotam reflexões e percepções que se deram no e a partir do desenvolvimento de cada aula (LÜDKE e ANDRÉ, 1986).

Para compreender as especificidades da turma em relação à língua de sinais, foi constituído um Questionário Semiestruturado para reunir informações de maneira similar a uma entrevista (LÜDKE e ANDRÉ, 1986). Desenvolvido em 2 horas/aula, o questionário permitiu construir o perfil particular de cada participante, conhecendo os tipos de surdez - leve, moderada, severa, profunda —, o uso, ou não, de próteses auditivas, a fluência em Libras e a habilidade com o português escrito, bem como as estratégias de comunicação utilizadas no cotidiano e no grupo familiar (oralização, língua de sinais, leitura labial...) e o rendimento escolar (reprovações) do grupo.

Para o reconhecimento dos significados já consignados pelo grupo de estudantes, sobre conceitos e propriedades de números reais, foram elaboradas algumas atividades que compõem uma Tarefa Prognóstica, com intuito de identificar possíveis lacunas de aprendizagem antecipando possibilidades de estratégias didáticas (HOFFMANN, 2017). Essa foi realizada em 4 horas/aula, com questões envolvendo os tópicos abordados na Sequência de Tarefas, a análise da Tarefa Prognóstica foi útil para o planejamento e organização de conteúdos matemáticos abordados em cada intervenção. 
No desenvolvimento da tarefa supracitada alguns termos matemáticos foram discutidos e conceituados para se estabelecer sinais em Libras, como foi o caso de área, conjunto numérico e radiciação, por exemplo. Na Tarefa Prognóstica, a turma teve o primeiro contato com o tangram, assim a geometria das peças ganhou ênfase para estabelecer sinais às suas formas — triângulos, quadrado e paralelogramo.

A partir da reflexão sobre as experiências produzidas no desenvolvimento da tríade de ações a priori a Sequência de Tarefas teve seus enunciados adaptados, aproximando-os da estrutura da língua de sinais, e em seguida foi desenvolvida em sete intervenções no horário regular da disciplina de Matemática, totalizando 14 horas/aula. Essa sequência envolveu uma série de atividades e materiais didáticos, com intuito de explorar propriedades e representações de números reais (Figura 4).

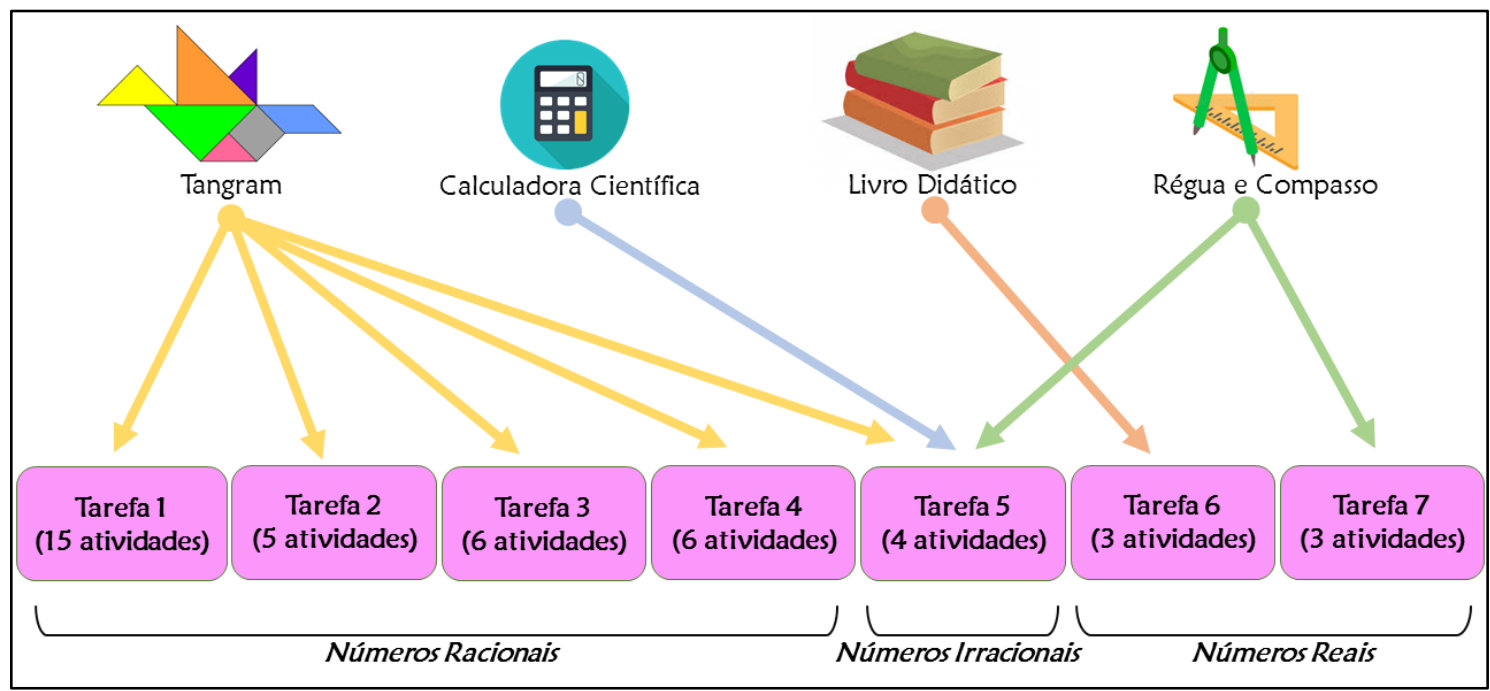

Figura 4: Material manipulável e recursos didáticos envolvidos em cada tarefa (Acervo da Pesquisa)

As quatro primeiras tarefas abordam números racionais, com ênfase na exploração de relações parte-todo, operador e medida, ainda anuindo um estudo sobre a equivalência fracionária. A quinta tarefa centra-se no estudo de números irracionais, iniciando a exploração de construções geométricas de medidas incomensuráveis. As duas últimas tarefas aliam, respectivamente, um livro didático de Matemática e construções geométricas para o estudo de números reais. Problematizações relacionadas a propriedades da densidade e completude de conjuntos ganham ênfase na medida em que o tangram vai perdendo espaço nas atividades, com intuito de que o material manipulável não seja mais utilizado para a mobilização dos conceitos, sendo este um dos direcionamentos propostos por Lorenzato (2006). 
Sob a ótica semio-cognitivo, identifica-se que apreensões em Geometria foram mobilizadas no desenvolvimento da Sequência de Tarefas, cumprindo assim com as quatro operações mentais necessárias à análise de figuras (DUVAL, 2012a, 2012b). Em especial, a apreensão operatória em tratamentos figurais, efetuados a partir da manipulação no tangram, e a apreensão sequencial pela construção/reprodução de figuras geométricas (SOUZA e MARIANI 2020). Destarte, a seção a seguir ocupa-se de considerações sobre outro olhar, de um ponto de vista sobre os materiais didáticos envolvidos nessa práxis.

\section{Caminhos e descaminhos da práxis: uma análise sobre os materiais didáticos}

Para estabelecer essa discussão, tecemos análises relacionadas as contribuições e limites do tangram, das calculadoras científicas, do livro didático e da régua e compasso diante da dinamização da Sequência de Tarefas. Doravante, cada um dos materiais será destacado, explicitando esse desenvolvimento.

O tangram não era conhecido pela turma, sendo o primeiro contato efetivado na Tarefa Prognóstica. Assim, para convencionar designações em Libras do material e suas peças, as formas geométricas que compõem o recurso foram utilizadas. No caso das palavras "triângulo" e "quadrado", foi possível identificar designações junto ao dicionário ilustrado de Libras (CAPOVILLA e RAPHAEL, 2008). Já para a palavra "paralelogramo", a turma estabeleceu duas designações (sinais sinônimos) estritamente relacionados às características visuais da peça (sinal icônico), utilizando representações desenhadas das figuras para fins de comunicação.

O material foi aliado nas Tarefas 1 e 2 possibilitando gerar figuras em uma relação parte todo, para realizar explorações voltadas aos números racionais. Definida a unidade (quadrado de sete peças), a decomposição da figura sob a forma de cada peça — que foi permitida pela manipulação — respaldou a mobilização de representações fracionárias numéricas, atribuindo simultaneamente relações com os parâmetros (GESSER, 2009) dos respectivos sinais em Libras (Figura 5). 


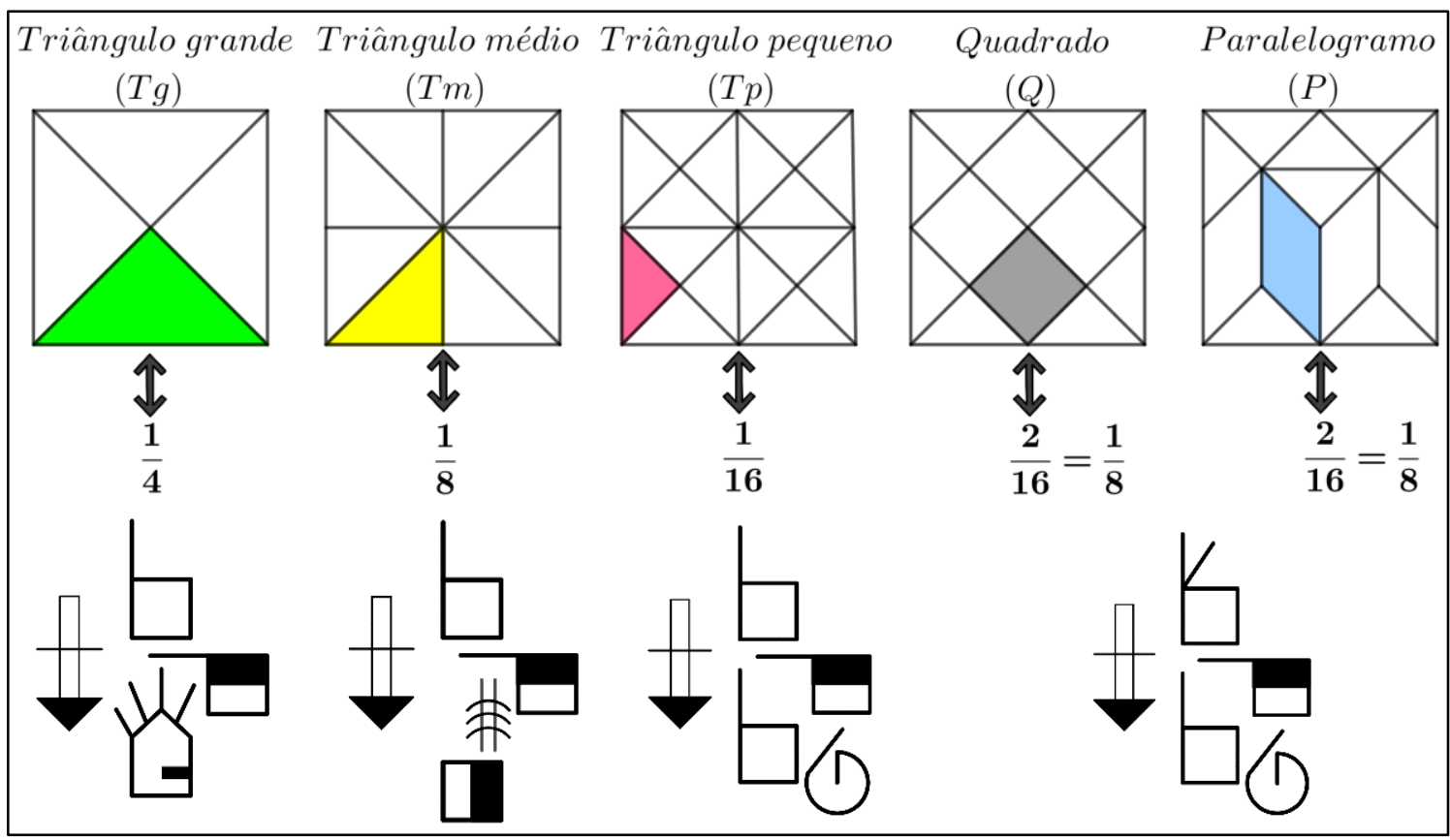

Figura 5: Representações fracionárias mobilizadas a partir das peças do tangram (Acervo da Pesquisa)

O tangram também permitiu combinar duas peças Tp de distintas maneiras, explorando translações, rotações e a justaposição de figuras planas. Em particular, a forma das peças $\mathrm{P}$, Q e Tm podem ser geradas com duas peças Tp, o que foi abordado na Tarefa 2. A análise destas organizações possibilitou concluir a congruência das áreas de P, Q e Tm (Figura 6), sendo $\frac{1}{8}$ ao tomar como referência da área conhecida de Tg e, ao mesmo tempo, $\frac{2}{16}$ se considerada a área de duas peças Tp.

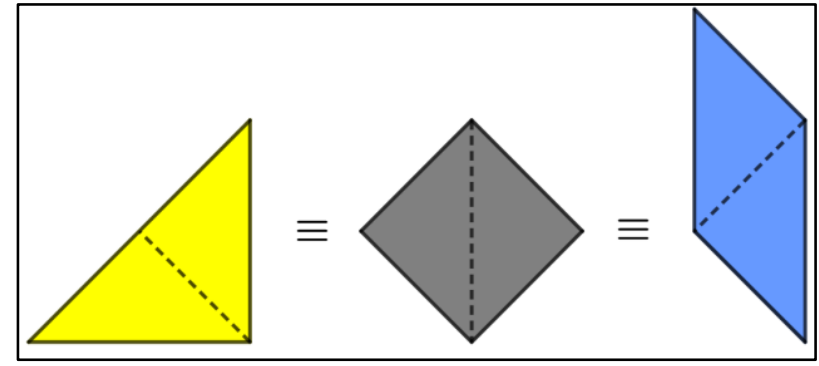

Figura 6: Congruência de área entre peças do tangram (Acervo da Pesquisa)

Nas Tarefas 3 e 4, números racionais foram explorados como pontos sobre um segmento de reta, mobilizando representações geométricas, que podem contribuir com as formas de memória específicas da pessoa surda (SACKS, 1998), pois sua apreensão de elementos é simultânea e bidimensional (DUVAL, 2009), como na língua de sinais. Também se exploraram representações percentuais e decimais, a fim de constituir a tríade numérica representativa racional, cujo entendimento do conceito depende da consonância 
entre elas (DAMM, 1999; DUVAL, 2003).

Os tratamentos figurais possibilitados na manipulação do tangram, em específico aqueles da relação parte-todo, auxiliaram a conversão para representação geométrica, numérica percentual e decimal nas Tarefas 3 e 4 . A ideia de decompor a figura unitária foi transposta para a representação geométrica em que o segmento de reta foi decomposto, em quatro partes congruentes para identificar o ponto $\frac{1}{4}=0,25$, por exemplo. A lógica de divisão ainda foi aproveitada para analisar um todo representado como $100 \%$, sendo sua quarta parte correspondente a $25 \%$.

Nesse sentido, as relações constituídas a partir do material manipulável contribuíram com a estruturação lógica do pensamento quando os sistemas de representação eram alterados. Construir uma figura com valor de área racional limitada ao intervalo $[0,25 ; 0,75]$ na Tarefa 3 , deu vistas para discutir propriedades da densidade de conjuntos, pois sempre é possível identificar um número racional em um intervalo fechado racional. Já na Tarefa 4, o tangram colaborou com a constituição do conceito de taxa percentual, que tinha significado muito limitado na turma, a partir de reduções de área do quadrado de sete peças, construindo um novo quadrado com as peças restantes do processo, em que se valeram reduções de 50\%, 25\% e 12,5\% da área (Figura 7).

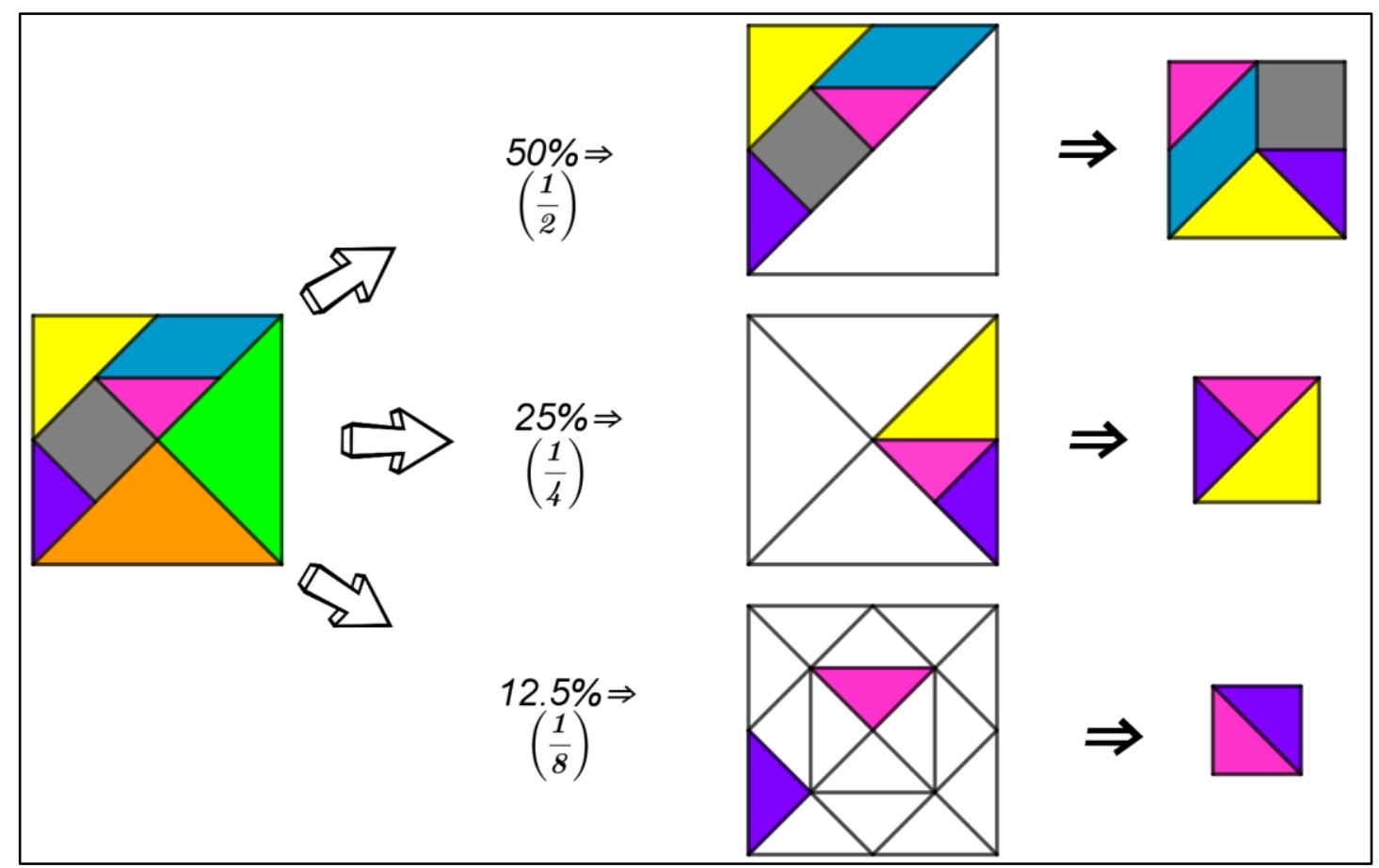

Figura 7: Congruência de área entre peças do tangram (Acervo da Pesquisa) 
O tangram ainda foi utilizado na Tarefa 5, em que se estabelece uma troca de unidade de medida, sendo agora a peça Quadrado do material. A partir disso, a aplicação do teorema de Pitágoras nos triângulos retângulos do material possibilita a mobilização das representações irracionais $\sqrt{8}$ (ou $2 \sqrt{2}$ ) e $\sqrt{2}$. A turma apresentou dificuldades relacionadas ao sistema de representação algébrico no desenvolvimento do teorema de Pitágoras, já que nunca haviam tido contato com operações algébricas, mesmo estando no Ensino Médio.

Desta forma, o material foi fundamental para a expansão do conjunto dos números racionais e para que se atribuísse um sentido à expressão $a^{2}+b^{2}=c^{2}$ e seu desenvolvimento, resultando como a medida $\sqrt{2}$ de um segmento. A manipulação do recurso igualmente promoveu comparações entre lados de peças, por sobreposições e justaposições, que possibilitaram que a turma concluísse que a hipotenusa da peça Tg é congruente ao dobro da medida $\sqrt{2}$, assim permitindo a mobilização da representação numérica irracional $2 \sqrt{2}$ por meio de operações em representações de figurais icônicas.

As calculadoras científicas utilizadas na Tarefa 5 também eram desconhecidas pelo grupo, até o início do desenvolvimento deste estudo. As atividades da sequência proposta foram planejadas a fim de explorar comandos básicos, como as quatro operações aritméticas, pela observação participante foi possível identificar que a turma não revelou dificuldades para usar as calculadoras. Por meio da análise dos dígitos disponíveis no visor do aparelho, as atividades permitiram estabelecer conjecturas sobre dízimas infinitas periódicas e não periódicas, o que possibilitou enfatizar números racionais e irracionais. Além disso, esse desenvolvimento oportunizou estabelecer comparações entre representações decimais de números racionais e de números irracionais, sendo que o uso da calculadora também foi essencial para destacar a simbologia matemática presente nas teclas e aquelas reproduzidas na tela.

Para implementar uma análise mais aprofundada sobre comparações de dízimas para o estudo do conceito de (ir)racionalidade, seguindo recomendações dispostas em documentos orientadores de ensino, advoga-se que com a calculadora podem ser obtidas sucessivas aproximações decimais de $\sqrt{2}$. Uma alternativa para isso é a aplicação do método da bissecção, que a partir de um intervalo aproximado inicial $[a ; b] ; a, b \in \mathbb{R}$, 
permite controlar o erro da aproximação por meio de iterações do tipo $\frac{a+b}{2}$. Ao analisar o resultado, se obtém um novo intervalo: ou $\left[a ; \frac{a+b}{2}\right]$ ou $\left[\frac{a+b}{2} ; b\right]$. Pode-se repetir o processo até uma aproximação com erro tão pequeno quanto se queira (Tabela 1).

Tabela 1: Método da bissecção na aproximação decimal de $\sqrt{2}$

\begin{tabular}{c|c|c|c|c|c}
\hline Iter. & $a$ & $b$ & $\frac{a+b}{2}$ & $\left(\frac{a+b}{2}\right)^{2}$ & Critério de escolha \\
\hline $1^{\mathrm{a}}$ & 1 & 2 & 1,5 & 2,25 & $(\sqrt{2})^{2}<(1,5)^{2}$ \\
\hline $2^{\mathrm{a}}$ & 1 & 1,5 & 1,25 & 1,5625 & $(1,25)^{2}<(\sqrt{2})^{2}$ \\
\hline $3^{\mathrm{a}}$ & 1,25 & 1,5 & 1,375 & 1,890625 & $(1,375)^{2}<(\sqrt{2})^{2}$ \\
\hline $4^{\mathrm{a}}$ & 1,375 & 1,5 & 1,4375 & 2,06640625 & $(\sqrt{2})^{2}<(1,4375)^{2}$ \\
\hline $5^{\mathrm{a}}$ & 1,375 & 1,4375 & 1,40625 & 1,977539063 & $(1,40625)^{2}<(\sqrt{2})^{2}$ \\
\hline $6^{\mathrm{a}}$ & 1,40625 & 1,4375 & 1,421875 & 2,021728516 & $(\sqrt{2})^{2}<(1,421875)^{2}$ \\
\hline $7^{\mathrm{a}}$ & 1,40625 & 1,421875 & 1,4140625 & 1,999572754 & $(1,4140625)^{2}<(\sqrt{2})^{2}$ \\
\hline $8^{\mathrm{a}}$ & $\mathbf{1 , 4 1 4 0 6 2 5}$ & $\mathbf{1 , 4 2 1 8 7 5}$ & 1,41796875 & 2,010635376 & $(\sqrt{2})^{2}<(1,41796875)^{2}$ \\
\hline $9^{\mathrm{a}}$ & $\mathbf{1 , 4 1 4 0 6 2 5}$ & $\mathbf{1 , 4 1 7 9 6 8 7 5}$ & 1,416015625 & 2,00510025 & $(\sqrt{2})^{2}<(1,416015625)^{2}$ \\
\hline $10^{\mathrm{a}}$ & $\mathbf{1 , 4 1 4 0 6 2 5}$ & $\mathbf{1 , 4 1 6 0 1 5 6 2 5}$ & 1,415039063 & 2,002335548 & $(\sqrt{2})^{2}<(1,415039063)^{2}$ \\
\hline$\vdots$ & $\vdots$ & $\vdots$ & $\vdots$ & $\vdots$ & $\vdots$ \\
\hline $21^{\mathrm{a}}$ & 1,414213181 & 1,414214134 & 1,414213657 & 2,000000269 & $(\sqrt{2})^{2}<(1,414213657)^{2}$ \\
\hline $22^{\mathrm{a}}$ & 1,414213181 & 1,414213657 & 1,414213419 & 1,999999594 & $(1,414213419)^{2}<(\sqrt{2})^{2}$ \\
\hline
\end{tabular}

Fonte: Elaborado pelas Autoras

$\mathrm{Na}$ Tabela 1, se exemplifica uma aproximação decimal de $\sqrt{2}$ pelo método da bissecção, na qual o intervalo inicial [1;2] é definido ao constatar a seguinte desigualdade $\sqrt{1}<\sqrt{2}<\sqrt{4}$, que pode ser reescrita como $1<\sqrt{2}<2$. Na $22^{\mathrm{a}}$ iteração se constata uma aproximação com precisão de 6 dízimas, e pode-se continuar o processo infinitamente.

O Livro Didático utilizado na Sequência de Tarefas - em particular, na Tarefa 6 — foi do $1^{\circ}$ ano do Ensino Médio, distribuído pelo Programa Nacional do Livro Didático para o Ensino Médio do ínterim 2009-2011 de autoria de Smole e Diniz (2005). Trata-se de um material não adaptado à comunidade surda, pois contém toda a abordagem 
exclusivamente em língua portuguesa, assim o planejamento desta Tarefa contou com a tradução das seções utilizadas para a língua de sinais, que foi efetivada na sala de aula, depois de buscar com que o grupo tentasse estabelecer a leitura do Português.

Ainda durante o desenvolvimento das ações a priori, foi constatado que a turma não tinha contato com um livro didático de Matemática. Desse modo, no início da Tarefa 6 foram destinados alguns minutos à exploração livre no livro. Nesse momento observouse expressiva curiosidade em toda turma, que também alegava não saber que tal obra estava disponível na biblioteca da escola, assim como outros exemplares relacionados às respectivas séries dos anos finais do Ensino Fundamental. O grupo "navegando" pelas páginas do livro didático, mantinha atenção majoritariamente nos conteúdos imagéticos, mostrando entre si figuras geométricas e demais representações visuais.

Desde o início das intervenções a leitura do Português foi estimulada na Sequência de Tarefas, que teve seus enunciados adaptados. Esse processo visava a busca de uma autonomia na leitura dos enunciados, que foi efetivada já na Tarefa 4, quando se percebia que quem finalizasse a atividade com antecedência tentava ler o português do enunciado seguinte, pois requisitavam auxílio sinalizando sua compreensão da atividade.

Durante a realização da Tarefa 6, no entanto, o grupo mostrou compreensão parcial do texto veiculado no livro didático, portanto foram efetivadas as traduções para a realização das atividades. Foram selecionadas as seções do livro referentes ao estudo do conjunto dos números racionais, irracionais e reais, contribuindo assim com formalizações sobre o conceito de (ir)racionalidade. A abordagem na obra enfatiza ainda a mobilização de números reais sobre a reta numérica, por justificar a existência de infinitos números racionais em um intervalo racional com representações geométricas, uma problematização intimamente relacionada à ideia de densidade de um corpo.

A Tarefa 6 se valeu do direcionamento pelo viés geométrico do livro, que ainda foi estendido, buscando a identificação geométrica de números irracionais num intervalo racional e, contrariamente, de números racionais num intervalo irracional. A proposta efetivada nas atividades compreende noções de completude dos números reais, pois, por exemplo, identificar um número não racional em um intervalo racional, em suma, é identificar um contraexemplo que justifica a não completude do conjunto dos racionais. 
Diante do exposto conclui-se que as dificuldades da turma frente ao livro didático estão vinculadas, provavelmente, à quantidade de informações e ao layout dos tópicos, que não são adaptados para língua de sinais ou com uma organização visuoespacial pensada para a comunidade. Entretanto, observa-se que políticas públicas deveriam garantir o direito de acesso linguístico inclusivo para pessoas surdas a esse tipo de material, com glosas e/ou vídeos com traduções para língua de sinais. A responsabilidade de traduzir as informações do livro não deveria recair sobre a equipe docente.

A Régua e Compasso foram empregados em construções geométricas de figuras planas na Tarefa 5. Assim sendo, as construções mobilizaram segmentos incomensuráveis (irracionais) sobre a reta numérica, oportunizando a identificação de números irracionais com a precisão geométrica, visto que sua representação numérica decimal pode ser considerada imprecisa pela não periodicidade de dízimas.

Como a turma indicou que já havia utilizado régua graduada, mas que nunca haviam realizado atividades com o compasso, o planejamento da Tarefa 5 incluiu algumas instruções prévias. Nesse momento foram distribuídos os dois instrumentos e foram implementadas algumas técnicas para transferir medidas, desconsiderando a graduação da régua. Pela turma não ter o hábito de segurar o compasso, algumas construções apresentam pequenas irregularidades, que não prejudicaram o estabelecimento das relações desenvolvidas: a construção de um segmento com medida $\sqrt{2}$ e $2 \sqrt{2}$.

$\mathrm{Na}$ Tarefa 7, a turma apresentou maior domínio sobre a ferramenta, desenvolvendo a construção, com régua e compasso, da Espiral de Teodoro, formada por triângulos retângulos cujas hipotenusas têm medidas $\sqrt{n} \operatorname{com} n=1,2,3,4 \ldots$, o que fomenta a mobilização de uma sequência de números reais. Barbosa (2009) identifica que crianças surdas podem apresentar dificuldades para adquirir a noção de uma ordenação numérica, assim a abordagem didática explorou elementos em representações visuais (geométrica e simultaneamente icônica) para consolidar o desenvolvimento de critérios para ordenação de uma sequência de números reais (Figura 8), realizada com êxito pela turma.

Para realizar esse processo, os segmentos hipotenusa de cada triângulo retângulo da espiral de Teodoro foram projetados sobre um segmento de reta, suas medidas, foram determinadas com apoio do teorema de Pitágoras. Mesmo com algumas dificuldades para 
realizar operações algébricas, realidade não distante de classes ouvintes, a turma estabeleceu a mobilização sinérgica entre representações geométricas, icônicas e numéricas, o que vem a dar qualidade na aprendizagem dos conceitos (DUVAL, 2009). Um fato interessante é que esse desenvolvimento permitiu identificar a congruência entre o segmento de medida $\sqrt{4}$ u.c. e a distância de zero até o número 2 na reta numérica.

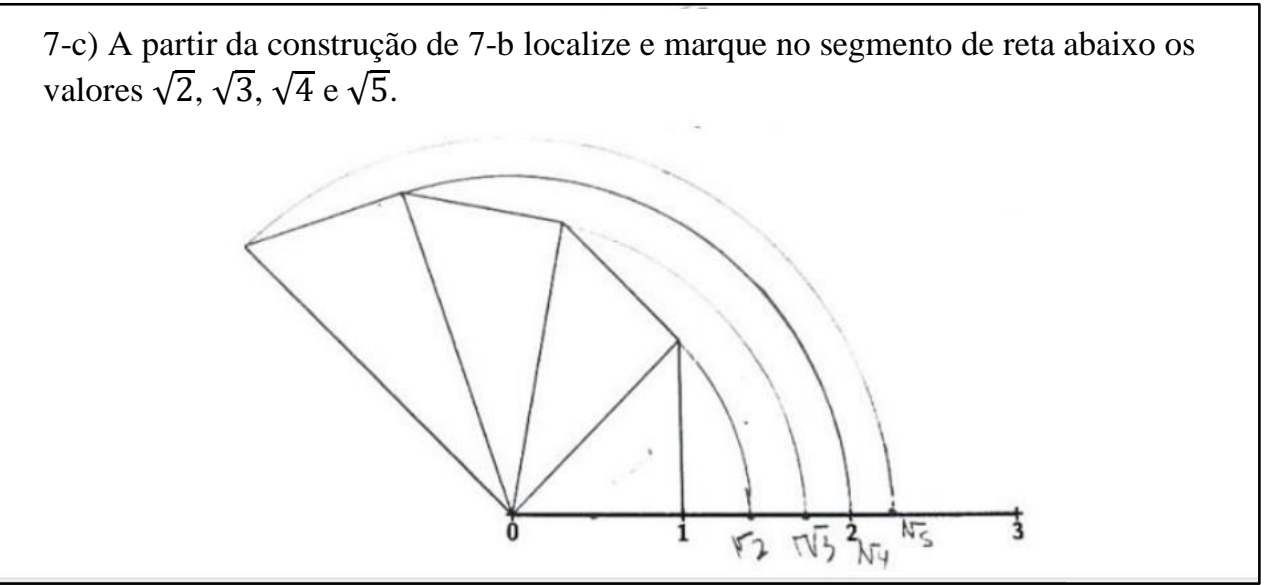

Figura 8: Espiral de Teodoro construída para mobilização de números reais (Acervo da Pesquisa)

Estabelecer a mobilização simultânea de dois sistemas representativos estritamente visuais para um mesmo objeto matemático — figural icônico nas construções e geométrico com os pontos no segmento de reta - contribuiu com os processos mentais visuoespaciais demandados na comunidade surda. Por outro lado, também se contemplam pressupostos teóricos dos registros de representação semiótica que garantem promoção de condições para efetivar processos de ensino e aprendizagem.

\section{Epílogo e palavras finais}

Meus olhos são meus ouvidos. Minhas mãos são bilíngues. Emmanuelle Laborit

Enquanto autoras consideramos que por meio deste artigo foram apontadas algumas (im)possibilidades diante do uso de materiais didáticos na práxis em aulas de Matemática para pessoas surdas. Essa abordagem tem o intuito de explicitar elementos que possam ser analisados por docentes e pessoas que pesquisam o ensino e aprendizagem de Matemática, aprofundando discussões sobre a educação matemática inclusiva no contexto da comunidade surda. Diante do exposto, destacamos que aulas com materiais manipuláveis podem contribuir nesse âmbito, como foi o caso do uso do tangram. Há também materiais que se mostram produtivos para inclusão nas aulas, no entanto, que 
ainda demandam ser adaptados, como ocorreu com o livro didático.

Vale destacar que os marcos aqui tratados são escolhas, pensadas para um contexto particular, então não devem ser entendidos como "O método" frente à educação de pessoas surdas, mas sim como um ensaio de possíveis direções. A seara inclusiva ainda possui muitas faces inexploradas, para seguir em frente ainda há muito chão a percorrer.

Algumas considerações importantes diante de uma turma com pessoas ouvintes e surdas incluídas, são elucidadas por Muniz, Peixoto e Madruga (2018), as quais consideramos importantes de ser reiteradas: devem ser realizadas reuniões de planejamento das aula de forma conjunta entre docentes e TILSP; ao incluir vídeos na aula, verificar a disponibilidade de legendas; se valer de uma dicção calma que permita um boa tradução para língua de sinais; evitar ditar enunciados e textos, pela datilologia extensa na tradução para Libras que dificulta a comunicação; docentes devem buscar conhecer a Libras aproximando-a de suas aulas.

Ademais, destacamos três fatores que se aparentam significativos para o encaminhamento de uma boa práxis quando a investigação ou aula envolve pessoas surdas: 1) Zelar pelo acesso às informações em língua de sinais, respeitando a cultura da comunidade surda já tão preterida socialmente; 2) Propor encaminhamentos didáticos que fazem uso de materiais manipuláveis que proponham a mobilização de distintas representações semióticas, em particular, as representações figurais; 3) Reconhecer a pluralidade da comunidade surda, que é atravessada por fatores interseccionais, um deles sendo as condições de acesso a estímulos linguísticos, que para Barbosa (2009) influenciam diretamente no rendimento escolar.

Como autoras, ainda vale ressaltar nosso lugar de fala (RIBERO, 2019) enquanto ouvintes, no qual nossa pretensão é contribuir com o avanço científico do conhecimento sobre o ensino e a aprendizagem de matemática na comunidade surda. A construção de alternativas para democratizar espaços, tanto físicos como sociais, presume conhecer as necessidades dos grupos a ser incluídos. Assim, nosso contato com a comunidade surda na EEEERFC pode ser produtivo nesse sentido, diante das poucas investigações na área.

\section{Agradecimentos}

Por fim, cabe deixar alguns agradecimentos... Um especial, à turma que participou da pesquisa, nesse grande tempo de convivência em sala de aula criamos laços sinceros de 
amizade. À toda equipe da EEEERFC, que também deve ser lembrada pela parceria e acolhimento. À educação de qualidade em uma universidade pública federal brasileira, ao EMgep/UFSM Educação Matemática: grupo de estudos e pesquisa, e ao apoio financeiro da CAPES (sob o código 001).

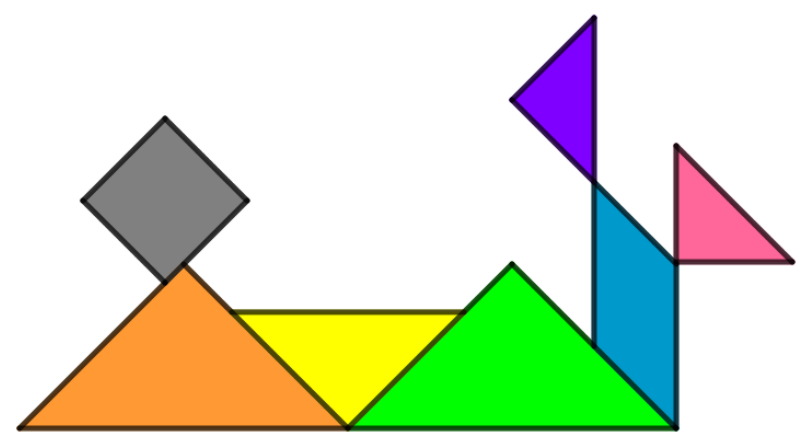

\section{Referências}

BARBOSA, Heloíza. O desenvolvimento cognitivo da criança surda focalizado nas habilidades visual, espacial, jogo simbólico e Matemática. In: QUADROS, Ronice Müller de; STUMPF, Marianne Rossi (Org.). Estudos Surdos IV. Petrópolis: Arara Azul, 2009. p. 407-424.

BIEMBENGUT, Maria Salett. Mapeamento na pesquisa educacional. Rio de Janeiro: Ciência Moderna, 2008.

BORGES, Fábio Alexandre; NOGUEIRA, Clélia Maria Ignatius. Um panorama da inclusão de estudantes surdos nas aulas de Matemática. In: NOGUEIRA, Clélia Maria Ignatius. (Org.). Surdez, inclusão e Matemática. Curitiba: CRV, 2013, p. 43-70.

BRASIL. Constituição da República Federativa do Brasil. Brasília: Diário Oficial da União, 5 out. 1988.

BRASIL. Decreto n. 5.626, de 22 de dezembro de 2005. Regulamenta a Lei n. 10.436 de 24 de abril de 2002, que dispõe sobre a Língua Brasileira de Sinais, e o art. 18 da Lei n. 10.098. Brasília: Diário Oficial da União, 22 dez. 2005.

BRASIL. Lei $n$. 10.436, de 24 de abril de 2002. Dispõe sobre a Língua Brasileira de Sinais - Libras e dá outras providências. Brasília: Diário Oficial da União, 24 abr. 2002.

BRASIL. Lei n. 12.319, de 1 de setembro de 2010. Regulamenta a profissão de Tradutor e Intérprete da Língua Brasileira de Sinais. Brasília: Diário Oficial da União, 1 set. 2010.

BRASIL. Lei n. 13.146, de 06 de julho de 2015. Institui a Lei Brasileira de Inclusão da Pessoa com Deficiência (Estatuto da Pessoa com Deficiência). Brasília: Diário Oficial da União, 6 jul. 2015.

BRASIL. Lei n. 9.394, de 20 de dezembro de 1996. Estabelece as Diretrizes e Bases da Educação Nacional. Brasília: Diário Oficial da União, 20 dez. 1996. 
BRASIL. Ministério da Educação. Declaração de Salamanca: sobre princípios, políticas e práticas na área das necessidades educativas especiais. Brasília: MEC, 1994.

BRASIL. Ministério da Educação. Secretaria de Educação Média e Tecnológica. Base Nacional Comum Curricular: Ensino Médio. Brasília: MEC/SEMT, 2018.

CAPOVILLA, Fernando César; RAPHAEL, Walkiria Duarte. Dicionário enciclopédico ilustrado trilíngue da Língua de Sinais Brasileira. 3. ed. São Paulo: EdUSP, 2008.

COUTINHO, Maria Dolores Martins da Cunha. A constituição de saberes num contexto de educação bilíngue para surdos em aulas de Matemática numa perspectiva de letramento. 2015. 268f. Tese (Doutorado em Educação) — Faculdade de Educação. Universidade Estadual de Campinas. Campinas.

DAMM, Regina Flemming. Registros de Representação. In: MACHADO, Silvia Dias Alcântara. (Org.). Educação Matemática: uma introdução. São Paulo: Educ, 1999, p. 135154.

DUVAL, Raymond. Abordagem cognitiva de problemas de geometria em termos de congruência. Tradução de Méricles Thadeu Moretti. Revemat, Florianópolis, v. 7, n. 1, p. 118-138, 2012a.

DUVAL, Raymond. Registro de representações semióticas de funcionamento cognitivo do pensamento. Tradução de Méricles Thadeu Moretti. Revemat, Florianópolis, v. 7, n. 2, p. 266-297, dez. 2012b.

DUVAL, Raymond. Registros de representações semióticas e funcionamento cognitivo da compreensão em matemática. In: MACHADO, Silvia Dias Alcântara (Org.). Aprendizagem em Matemática: registros de representação semiótica. Campinas: Papirus, 2003, p. 11-33.

DUVAL, Raymond. Semiósis e pensamento humano: registros semióticos e aprendizagens intelectuais. Tradução de Lênio Fernandes Levy e Marisa Rosâni Abreu da Silveira. São Paulo: Livraria da Física, 2009.

DUVAL, Raymond. Ver e ensinar a Matemática de outra forma: entrar no modo matemático de pensar os registros de representação semiótica. Tradução de Marlene Alves Dias. São Paulo: PROEM, 2011.

FRIZZARINI, Silvia Terezinha. Estudo dos registros de representação semiótica: implicações no ensino a aprendizagem da álgebra para alunos surdos fluentes em língua de sinais. 2014. 288f. Tese (Doutorado em Educação para a Ciência e Matemática) Centro de Ciências Exatas. Universidade Estadual de Maringá. Maringá.

GESSER, Audrei. LIBRAS? Que língua é essa?: crenças e preceitos em torna da língua de sinais e da realidade surda. São Paulo: Parábola Editorial, 2009.

GIL, Rita Sidmar Alencar. Educação Matemática dos surdos: um estudo das necessidades formativas dos professores que ensinam conceitos matemáticos no contexto de educação de deficientes auditivos em Belém/PA. 2007. 191f. Dissertação (Mestrado 
em Educação em Ciências e Matemáticas) - Instituto de Educação Matemática e Científica. Universidade Federal do Pará. Belém.

HOFFMANN, Jussara Maria Lerch. Avaliar para promover: as setas do caminho. Porto Alegre: Mediação, 2017.

JESUS, Thamires Belo de. (Des)construção do pensamento geométrico: uma experiência compartilhada entre professores e uma aluna surda. 2014. 183f. Dissertação (Mestrado em Educação em Ciências e Matemática) - Instituto Federal do Espírito Santo. Vitória.

KARNOPP, Lodenir Becker; KLEIN, Madalena; LUNARDI-LAZZARIN, Márcia Lise. Relatório final do projeto produções culturais surdas no contexto da educação bilíngue (2014-2018) - CNPq, processo 454906/2014-5. Pelotas; Porto Alegre; Santa Maria: Grupo Interinstitucional de Pesquisa em Educação de Surdos (GIPES), 2018.

LACERDA, Cristina Broglia Feitosa de. Um pouco da história das diferentes abordagens na educação dos surdos. Cadernos CEDES, Campinas, v. 19, n. 46, p. 68-80, set. 1998.

LORENZATO, Sergio. Laboratório de ensino de Matemática e materiais didáticos manipuláveis. In: LORENZATO, Sergio. (Org.). O laboratório de ensino de Matemática na formação de professores. Campinas: Autores Associados, 2006, p. 3-37.

LÜDKE, Menga; ANDRÉ, Marli. Pesquisa em Educação: abordagens qualitativas. São Paulo: EPU, 1986.

MUNIZ, Salvador Cardoso Silva; PEIXOTO, Jurema Lindote Botelho; MADRUGA, Zulma Elizabete de Freitas. Desafios na inclusão de surdos na aula de matemática. Revista Cocar, Belém, v. 1, n. 23, p. 215-239, jan./jun. 2018.

PINHEIRO, Fabrício Andrade; MUNIZ, Salvador Cardoso Silva; PEIXOTO, Jurema Lindote Botelho; MADRUGA, Zulma Elizabete de Freitas. Ensino de Matemática para surdos: mapeamento de pesquisas sobre resolução de problemas. Educação Matemática Debate, Montes Claros, v. 4, n. 10, p. 1-23, 2020.

RIBEIRO, Djamila. Lugar de fala. São Paulo: Sueli Carneiro; Pólen, 2019.

RIO DE JANEIRO. Federação Nacional de Educação e Integração dos Surdos (FENEIS). A educação que nós surdos queremos. Documento elaborado no pré-congresso ao $\mathrm{V}$ Congresso Latino-Americano de Educação Bilíngue para Surdos. Porto Alegre: Universidade Federal do Rio Grande do Sul, 1999.

RIO GRANDE DO SUL. Secretaria de Estado da Educação. $8^{\text {a }}$ Coordenadoria de Educação. Projeto Político Pedagógico da Escola Estadual de Educação Especial Doutor Reinaldo Fernando Cóser. Santa Maria: SEE-RS/CRE 08, 2018.

ROCHA, Fernanda Bittencourt Menezes. Ensinando geometria espacial para alunas surdas de uma escola pública de Belo Horizonte (MG): um estudo fundamentado na perspectiva histórico-cultural. 2014. 199f. Dissertação (Mestrado em Educação Matemática) - Instituto de Ciências Exatas e Biológicas. Universidade Federal de Ouro 
Preto. Ouro Preto.

SACKS, Oliver Wolf. Vendo vozes: uma viagem ao mundo dos surdos. Tradução de Laura Teixeira Mota. São Paulo: Companhia das Letras, 1998.

SALES, Elielson Ribeiro de. A visualização no ensino de matemática: uma experiência com alunos surdos. 2013. 237f. Tese (Doutorado em Educação Matemática) — Instituto de Geociências e Ciências Exatas. Universidade Estadual Paulista. Rio Claro.

SMOLE, Katia Stocco; DINIZ, Maria Ignez. Matemática: Ensino Médio. 5. ed. São Paulo: Saraiva, 2005.

SOARES, Maria Eliana; SALES, Elielson Ribeiro de. Uma reflexão sobre pesquisas em Educação Matemática e Educação de Surdos. Educação Matemática Debate, Montes Claros, v. 2, n. 4, jan./abr. 2018.

SOUZA, Lucas José de. Surdez no contexto da Educação Matemática: um estudo sobre o conjunto dos números reais a partir de registros de representação semiótica e o tangram. 2019. 223f. Dissertação (Mestrado em Educação Matemática e Ensino de Física) Centro de Ciências Naturais e Exatas. Universidade Federal de Santa Maria. Santa Maria.

SOUZA, Lucas José de; GUIMARÃES, Tainara da Silva; MARIANI, Rita de Cássia Pistóia. Surdez e Educação Matemática: um mapeamento de trabalhos stricto sensu produzidos no Brasil. In: ESCOLA DE INVERNO DE EDUCAÇÃO MATEMÁTICA, 6, 2018, Santa Maria. Anais da VI EIEMAT: Desafios e possibilidades na Educação Matemática: para onde estamos caminhando? Santa Maria: UFSM, 2018, p. 1040-1055.

SOUZA, Lucas José de; MARIANI, Rita de Cássia Pistóia. Números reais no contexto de uma comunidade escolar surda: um estudo com ênfase em registros figurais. Ensino da Matemática em Debate, São Paulo, v. 7, n. 1, p. 138-167, 2020.

TEIXEIRA, Beneilde de Fátima Chagas. Geometria perceptiva, arte e informática na educação de surdos nas séries iniciais. 2008. 100f. Dissertação (Mestrado em Educação em Ciências e Matemáticas) — Instituto de Educação Matemática e Científica. Universidade Federal do Pará. Belém.

VÁSZQUEZ, Adolfo Sanchéz. Filosofía de la praxis. Ciudad de México: siglo veintiuno, 2003.

YIN, Robert. Estudo de caso: planejamento e método. 3. ed. Porto Alegre: Bookman, 2005.

ZANQUETTA, Maria Emilia Melo Tamanini. Uma investigação com alunos surdos do Ensino Fundamental: o cálculo mental em questão. 2015. 260f. Tese (Doutorado em Educação para a Ciência e Matemática) - Centro de Ciências Exatas. Universidade Estadual de Maringá. Maringá. 